ORIGINAL ARTICLE

\title{
Latent classes of criminal intent associated with criminal behaviour
}

\author{
Daniel Boduszek ${ }^{A, B, C, D}$, Katie Dhingra ${ }^{E, F}$, Camille Stander ${ }^{A, F}$, Maria Ioannou $^{E}$, Derrol Palmer ${ }^{A, E}$ \\ University of Huddersfield, Huddersfield, West Yorkshire, Great Britain
}

BACKGROUND

This study aimed to examine the number of latent classes of criminal intent that exist among prisoners and to look at the associations with recidivism, number of police arrests, type of offending (robbery, violent offences, murder, and multiple offences), and age.

\section{PARTICIPANTS AND PROCEDURE}

Latent class analysis was used to identify homogeneous subgroups of prisoners based on their responses to the 10 questions reflecting criminal intent. Participants were 309 male recidivistic prisoners incarcerated in a maximum security prison. Multinomial logistic regression was used to interpret the nature of the latent classes, or groups, by estimating the association between recidivism and latent classes of criminal intent while controlling for offence type (robbery, violent offences, murder, and multiple offences), number of arrests, and age.
RESULTS

The best fitting latent class model was a three-class solution: 'High criminal intent' (49.3\%), 'Intermediate criminal intent' (41.3\%), and 'Low criminal intent' (9.4\%). The latent classes were differentially related to the external variables (recidivism, violent offences, and age).

\section{CONCLUSIONS}

Criminal intent is best explained by three homogeneous classes that appear to represent an underlying continuum. Future work is needed to identify whether these distinct classes of criminal intent may predict engagement in various types of criminal behaviour.

\section{KEY WORDS}

criminal intent; recidivism; prisoners; latent class analysis

CORRESPONDing AUthor - Daniel Boduszek, Ph.D., Department of Behavioural Sciences, University of Huddersfield,

Queensgate, Huddersfield, HD1 3DH, United Kingdom, e-mail: d.boduszek@hud.ac.uk

Authors' Contribution - A: Study design - B: Data collection · C: Statistical analysis · D: Data interpretation ·

E: Manuscript preparation · F: Literature search · G: Funds collection

to CITE This ARTICle - Boduszek, D., Dhingra, K., Stander, C., loannou, M. \& Palmer, D. (2014). Latent classes of criminal intent associated with criminal behaviour. Current Issues in Personality Psychology, 2(2), 92-102. 


\section{BACKGROUND}

Criminal thinking has been conceptualised as distorted thought patterns that support the commencement and continuation of offending behaviour (Walters, 2006). Extensive research demonstrates a link between criminal thought processes and antisocial behaviour (Andrews \& Kandel, 1979; Bagozzi \& Burnkrant, 1979; Engels, Luijpers, Landsheer \& Meeus, 2004; Gendreau, Goggin \& Law, 1997; Mills \& Kroner, 2003; Mills, Kroner \& Forth, 2002; Mills, Kroner \& Hemmati, 2004; see Boduszek \& Hyland, 2012 for a review). Indeed, along with antisocial associations, meta-analytic studies find that criminal/antisocial attitudes are among the strongest predictors of future delinquency (Gendreau, Little \& Goggin, 1996; Simourd, Hoge, Andrews \& Leschied, 1994). Gendreau et al. (1996), for instance, in a meta-analysis of 37 studies, reported that among six groups of risk factors, antisocial attitudes/associates provided the strongest correlation with criminal conduct $(r=0.22)$.

One of the first theoretical considerations of criminal thinking was Sutherland's Differential Association Theory. According to this theory, criminal attitudes are the product of association with criminals. Thus, association with criminal peers is considered to be the root cause of criminal conduct (Sutherland \& Cressey, 1978; Sutherland, Cressey \& Luckenbill, 1992). Similarly, Akers (1985) in his Differential Reinforcement Theory, suggested that individuals are first initiated into delinquent conduct though their association with antisocial others. Then, through social reinforcement, they gain knowledge of how to gain rewards and avoid punishment for the consequences (actual or anticipated) of particular conduct.

Neutralization theory has also contributed to the understanding of criminal thinking. Sykes and Matza (1957) postulated that criminals typically perceive themselves as conventional, rather than antisocial, and try to rationalise and justify their criminal acts. Sykes and Matza advanced five methods used by criminals to achieve this: denial of the victim ("he/she was asking for it"), denial of injury ("no one got hurt"), condemnation of the condemners ("society is the real criminal"), denial of responsibility ("it was an accident"), and appeals to higher authority ("I couldn't let my friends down"). These cognitive processes have been observed in both young and adult offenders. However, somewhat inconsistent with Sykes and Matza's theory, such thinking patterns have been identified by criminal psychologists as occurring prior to, rather than as a consequence of, the commission of a criminal act, thus acting as a predictor of criminal behaviour. These thinking patters have also been shown to play a significant role in maintaining criminal behaviour (Maruna \& Copes, 2005).

Yochelson and Samenow (1976) developed an early theoretical framework for conceptualising criminals' thought processes. Working with 240 recidivistic prisoners from St. Elizabeth's Hospital in Washington D.C., where most of the criminals had been diagnosed as "insane", Yochelson and Samenow noted that the criminal thinking process is present across criminals' entire existence, and identified 52 separate thinking errors that were grouped into three main categories: a) "automatic errors of thinking" (i.e., perceived emotional basis for criminal behaviour), b) "criminal thinking patterns" (i.e., negative extreme of a responsible-irresponsible continuum of thinking), and c) criminal thinking errors "from idea through execution" (i.e., pro-criminal thoughts that occur prior to, during, and after committing criminal behaviours) that they believed reflected the thinking patterns of the criminals.

More recently, building on the work of Yochelson and Samenow (1976), Walters (1990, 1995a, 1995b, $2002,2003,2006)$ developed what is widely regarded as the most influential and important model of criminal thinking: 'criminal lifestyle'. Central to Walters' theory is the contention that criminal behaviour is derived from thought patterns that serve to support and rationalise their behaviour. Although partially opposed to Yochelson and Samenow's (1976) conceptualisation of criminal thinking errors, Walters (1990) based his conceptualisation of criminal thinking on what he considered to be Yochelson and Samenow's major contributions. These contributions included the ideas that: a) criminals' law-breaking behaviour is based on free choice, b) continued criminal thinking is the primary expression of free choice, and c) developing a sense of responsibility for one's own behaviour is necessary for change. Based on these ideas, Walters (1995a) developed the Psychological Inventory of Criminal Thinking Styles (PICTS; Walters, 1995a) to measure eight distinct criminal thinking styles proposed to be instrumental in promoting and advancing criminality. These are: a) "Mollification" (i.e., rationalising action by blaming external factors); b) "Cutoff" (i.e., immediate disregard for thoughts that deter crime); c) "Entitlement" (i.e., a privileged self-regard that permits antisocial behaviour); d) "Power Orientation" (i.e., need for control over others, self, and the environment); e) "Sentimentality" (i.e., negating distressing feelings related to one's behaviour by performing good deeds); f) "Superoptimism" (i.e., overconfidence in one's ability to avoid negative results of one's behaviour); g) "Cognitive Indolence" (i.e., using quick and easy cognitive "shortcuts"); and h) "Discontinuity" (i.e., hesitancy and unreliability in thought and behaviour) (Walters, 1990, 2001). Walters posited that these thinking patterns, though interrelated, are distinct cognitive aspects of the criminal lifestyle. The eight PICTS scales have been found to correlate with measures of criminal background (Walters, 1995a; Walters, Elliot \& Miscoll, 1998), as well as future disciplinary and release outcomes (Walters \& Elliott, 1999). 
Based on research indicating that criminal thinking is not represented by a single factor or domain (Kroner \& Mills, 1998; Mills, Anderson, \& Kroner, 2002; Simourd \& Olver, 2002), Mills and Kroner (1999) developed a model of criminal thinking based on four dimensions: a) "Violence", b) "Entitlement", c) "Antisocial Intent" (also referred to as criminal intent and criminal social intent), and d) "Associates" (Measure of Criminal Attitudes and Associates [MCAA]; Mills $\&$ Kroner, 1999). In line with Ajzen's (1988) explanation of attitudes, the Violence, Entitlement, and Antisocial Intent sub-scales measure dispositions towards actions, whereas the Associates sub-scale measures dispositions towards others. Research using this scale has found that tolerance towards violence (e.g., "It's all right to fight someone if they stole from you" and "It's understandable to hit someone who insults you") is a stronger predictor of involvement in violence than all sociological and economic variables assessed (Caprara, Cinanni \& Mazzotti, 1989; Mills, Kroner \& Weekes, 1998), thus providing strong empirical support for the crucial role of cognitive processes in the emergence of criminal conduct.

Entitlement has also been highlighted in theories of criminal thinking as important in explaining why people initiate criminal behaviour. Walters and White (1989) described entitlement as the cognition that "tells them they have a right to take whatever they want from whoever has what they desire" (p. 4). Items from the MCAA Entitlement scale include "Taking what is owed you is not really stealing" and "A lack of money should not stop you from getting what you want”. Research indicates that entitlement is one of two cognitions most highly associated with age of first arrest and age of first imprisonment (Walters, 1995a, 1995b). Previous research also indicates that the Alienation Scale of the Basic Personality Inventory (Jackson, 1989) is predictive of criminal conduct (Kroner, Holden \& Reddon, 1997; Palmer, 1997).

The present study focuses on the Antisocial intent subscale of the MCAA (a specific component of criminal thinking) as behavioural intentions have consistently been found to be better predictors of future behaviour than general attitudes (Ajzen, 1988; Ajzen $\&$ Fishbein, 1980). Sample items from the MCAA Antisocial Intent scale are "I could see myself lying to the police" and "I would run a scam if I could get away with it".

\section{CRIMINAL INTENT, RECIDIVISM, AND NUMBER OF ARRESTS}

Several studies have shown that criminal attitudes, particularly behavioural intentions (intent), have predictive validity for future general and violent recidivism (e.g., Mills et al., 2004; Palmer \& Hollin, 2004; Simourd \& van de Ven, 1999; Walters \& Elliott, 1999).
Walters (2002), for instance, found that the Current scale of the Psychological Inventory of Criminal Thinking Styles (PICTS) was predictive of recidivism, across different samples, even after controlling for scores on the Historical scale. Furthermore, a metaanalysis of 131 studies found that the top five predictors of recidivism were: criminal friends, antisocial cognitions (attitudes), antisocial personality, and adult criminal history (Gendreau, Little \& Goggin, 1996). Moreover, Mills et al. (2004) reported that the antisocial attitudes subscale (criminal intent) of the MCAA significantly improved the prediction of recidivism over an actuarial risk assessment alone.

Hanson and Harris (2000) found that recidivist sex offenders were more likely than non-recidivists to have tolerant attitudes towards sexual assaults, antisocial lifestyles and negative social influences. Moreover, these dynamic variables distinguished recidivists from non-recidivists even after controlling for static risk variables, such as age, IQ, and scores on established actuarial scales (e.g. Static-99, Hanson \& Thornton, 1999; Violence Risk Appraisal Guide, Quinsey, Harris, Rice \& Cormier, 1998).

Holsinger (1999) suggested that individuals who have been socialised in criminal settings, and who have acquired antisocial attitudes relating to criminal behaviour (i.e., crime congruent thoughts), are at the greatest risk of recidivism. Building on this, Boduszek, McLaughlin, and Hyland (2011), in a sample of 64 Irish ex-offenders, explored the influence of psychoticism, associations with criminal friends, and levels of recidivism on criminal attitudes. The results indicated that $71 \%$ of variance in criminal attitudes was explained on the basis of these variables, with psychoticism the strongest predictor of criminal attitudes, followed by association with criminal friends and levels of recidivism.

Targeting criminal attitudes has also been suggested to be an effective way of reducing repeat offending. Andrews, et al. (1990) found that intensive treatment programmes that target criminogenic needs were the most effective in reducing repeat offending. One of the primary criminogenic needs was found to be faulty cognitive styles (i.e., criminal thinking).

\section{CRIMINAL INTENT AND OFFENCE TYPE}

Although certain thinking styles promote criminal behaviour, these criminogenic cognitions may not be engaged in equally by different offender groups (Polaschek, Collie \& Walkey, 2004; Wilson, Attrill \& Nugent, 2003). Sex offenders and white-collar criminals are two groups of offenders that typically score lower than other offenders on criminal thinking scales (Hatch-Maillette, Scalora, Huss \& Baumgartner, 2001; Mills et al., 2004). Walters and Geyer (2004), for example, found that white-collar offenders exhibited 
fewer criminal attitudes and were less likely to identify with a criminal lifestyle than non-white-collar offenders. Individuals were classified as white-collar offenders if their charge was one of 10 charges: antitrust offenses, securities and exchange fraud, postal/ wire fraud, false claims/statements, credit fraud, bank embezzlement, tax fraud, bribery, health care fraud, and counterfeiting. Similar findings were reported by Ragatz, Fremouw, and Baker (2012).

\section{CRIMINAL INTENT AND AGE}

A consistent finding in the literature is that increased age is associated with lower levels of criminal thinking (e.g., Dembo, Turner \& Jainchill, 2007; Palmer \& Hollin, 2003; Walters, 2003). Walters (2003), for instance, reported that age was negatively correlated with the Psychological Inventory of Criminal Thinking Styles (PICTS; Walters, 1995b) Interpersonal Hostility scale, while Palmer and Hollin (2003) found that young offenders (i.e., aged 18 to 22 years) had significantly higher PICTS Cutoff, Superoptimism, Cognitive Indolence, and Discontinuity scores than older offenders. Other studies, however, have found no significant relationship between age and criminal thinking in adult offenders (e.g., Mandracchia \& Morgan, 2010, 2012; Walters \& Schlauch, 2008). No studies to date, however, have found age to be positively correlated with criminal thinking.

\section{CURRENT STUDY}

Although there is consistent evidence that criminal intent (also referred to as antisocial intent) is an important predictor of criminal behaviour, including recidivism, little is known about the predictors of criminal intent (see, however, Boduszek \& Hyland, 2012) or whether criminal intent should be conceptualized as dichotomous (i.e. present or absent) or dimensional (encompassing discrete classes). The aim of this study is, therefore, to identify the appropriate number of latent classes of criminal intent among recidivistic prisoners, and to identify the significant predictors of latent classes of criminal intent with a specific focus on recidivism levels while controlling for number of police arrests, current age, and offence type (violent offences, murder, multiple offence types).

\section{PARTICIPANTS AND PROCEDURE}

\section{MATERIAL AND METHODS}

The sample included 309 male recidivistic prisoners incarcerated in a maximum security prison. Of the prisoners, 86 were burglars and thieves, 68 violent offenders, 25 murderers, 18 drug dealers, 7 addicted thieves, 2 sex offenders and the remaining 103 were mixed offenders. Participants ranged in age from 20 to 66 years $(M=33.85, S D=9.38)$. The majority of the offenders came from urban areas $(88.1 \%, n=275)$. Just over half of offenders $(52.2 \%, n=163)$ reported having primary school education, $45.5 \%(n=142)$ secondary school education, and $2.2 \%(n=7)$ some college or university education. The largest proportion of participants $(68.3 \%, n=213)$ indicated their marital status as single, $11.9 \%(n=37)$ as married, $18.6 \%$ $(n=58)$ as divorced or separated, and $1.3 \%(n=7)$ as widowed. The frequency of imprisonment reported by offenders ranged from 1 (mostly murderers) to 19 times $(M=3.57, S D=2.48)$ and the number of reported police arrests from 1 to $20(M=4.85, S D=4.09)$.

Participants completed anonymous self-administered paper-and-pencil questionnaires. Each prisoner received a brief description of the study, was assured about the confidentiality of their participation, and informed that they had the right to withdraw from the study at any time. After completion of the questionnaire in their living units, participants were asked to return them to the prison educational coordinator in a sealed envelope. As participation was entirely voluntary, they were not given a reward for their participation.

\section{MEASURES}

For the present research, twelve questions reflecting criminal intent were used (see Mills et al., 2002; Mills $\&$ Kroner, 2001), and dummy coded for analysis (see Table 1).

A demographic questionnaire assessed respondents' age (continuous variable), number of arrests (count variable), recidivism (i.e., number of times incarcerated, count variable), and type of crime leading to incarceration (robbery, violent offences, murder, and multiple offences).

All questionnaires used in the current study were translated into Polish by a professional translator. In order to ensure that the meaning of the original inventories had been retained, the Polish versions were translated back into English. Both original translations and back-translations were then shown to three experts in translation who suggested minor changes.

\section{ANALYSIS}

Latent class analysis (LCA) is a statistical method used to identify homogeneous groups (classes) from categorical multivariate data. Latent class analysis may be used to find distinct diagnostic categories (or risk groups) through the presence/absence of several indicators. Latent class analysis was used to determine the number and nature of the latent classes of crim- 
Table 1

Frequency of endorsement the Criminal Intent items

\begin{tabular}{ccc}
\hline Item & Yes & $\%$ \\
\hline $\begin{array}{c}\text { 1. I would keep any amount } \\
\text { of money I found. }\end{array}$ & 239 & 76.6 \\
$\begin{array}{c}\text { 2. I could see myself lying to } \\
\text { the police. }\end{array}$ & 274 & 87.7 \\
$\begin{array}{c}\text { 3. In certain situations I would try } \\
\text { to outrun the police. }\end{array}$ & 224 & 71.8 \\
$\begin{array}{c}\text { 4. I would be open to cheating } \\
\text { certain people. }\end{array}$ & 255 & 81.7 \\
$\begin{array}{c}\text { 5. I could easily tell a convincing lie. } \\
\text { 6. Rules will not stop me from } \\
\text { doing what I want. }\end{array}$ & 170 & 54.5 \\
$\begin{array}{c}\text { 7. I would run a scam if I could get } \\
\text { away with it. }\end{array}$ & 226 & 72.4 \\
$\begin{array}{c}\text { 8. For a good reason, I would } \\
\text { commit a crime. }\end{array}$ & 211 & 67.6 \\
9. I will not break the law again* & 110 & 35.3 \\
$\begin{array}{c}\text { 10. I would be happy to fool } \\
\text { the police. }\end{array}$ & 243 & 77.9 \\
\hline
\end{tabular}

${ }^{*}$ Note. Item reverse coded

inal intent based on the endorsement of the 12 dummy coded items of the Criminal Intent subscale of the MCAA. Three latent class models were tested (2-class solution, 3-class solution, and 4-class solution). The optimal number of latent classes was selected on the basis of several statistical fit indices such as likelihood ratio chi-square (LR $\chi^{2}$ ), Akaike information criterion (AIC), Bayesian information criterion (BIC), sample size adjusted BIC (SSABIC), the Lo-Mendell-Rubin adjusted likelihood ratio test (LRT), and entropy measures. A non-significant LR $\chi^{2}$ indicates acceptable model fit. The information statistics AIC, BIC, and SSABIC are goodness of fit measures used to compare competing models; lower observed values indicate better fit. The LRT statistic was used to compare models with differing numbers of latent classes; a non-sig- nificant value $(p>0.05)$ suggests that the model with one fewer class should be accepted. Entropy is a standardised measure of how accurately participants are classified. Values range from 0 to 1 with higher values indicating better classification.

Multinomial logistic regression was used to assess the association between class membership (posterior probabilities from the model were used to assign individuals to a class) and age, number of arrests, recidivism, and four types of crime. The following odd ratios indicate the expected increase/decrease in the likelihood of scoring positively on a given variable compared to the reference, or control group. The LCA and multiple logistic model were conducted using Mplus 6.12.

\section{RESULTS}

\section{DESCRIPTIVE STATISTICS}

Table 2 presents the descriptive statistics for age, number of arrests, recidivism, and criminal intent, including means $(M)$ and standard deviations $(S D)$.

Table 1 shows the rates of endorsement for each of the items belonging to the Criminal Intent subscale of the MCAA. Due to significant missing values, two items were excluded (126 missing responses for "I am not likely to commit a crime in the future" and 58 for "I would not enjoy getting away with something wrong"). Endorsement rates for all 10 items relating to criminal intent were relatively high $(M=69.7 \%)$. The highest endorsement rates were for items 2 "I could see myself lying to the police" (87.7\%) and 4 "I would be open to cheating certain people" (81.7\%). By contrast, item 9 "I will not break the law again" was endorsed by relatively few participants (35.3\%).

\section{LATENT CLASS ANALYSIS OF CRIMINAL INTENT}

The fit indices for alternative latent class analyses are presented in Table 3. The 3-class solution is considered to be the best model; LR $\chi^{2}$ is non-significant and the information statistic (BIC) is marked lower than the 2- and 4-class solution. Most importantly,

Table 2

Descriptive statistics and correlations for age, number of arrests, recidivism, and criminal intent

\begin{tabular}{crrrcccc}
\hline Scale & $M$ & $S D$ & Range & Age & Arrests & Recidivism & Criminal Intent \\
\hline Age & 33.85 & 9.38 & $20-66$ & - & $0.13^{*}$ & $0.17^{* *}$ & $-0.18^{* *}$ \\
Arrests & 4.85 & 4.09 & $1-20$ & - & $0.69^{* *}$ & $0.20^{* *}$ \\
Recidivism & 3.57 & 2.48 & $1-19$ & - & & $0.18^{* *}$ \\
Criminal Intent & 6.97 & 2.53 & $0-10$ & & & & - \\
\hline Note. ${ }^{*} p<0.05 ;{ }^{* *} p<0.01$ & & & &
\end{tabular}


Table 3

Fit indices for the latent class analysis of the criminal intent

\begin{tabular}{ccccccccc}
\hline Model & LR $\chi^{2}(d f)$ & $p$ & AIC & BIC & SSABIC & LRT & $p$ & Entropy \\
\hline 2 classes & $638.870(1002)$ & 1.00 & 3114.406 & 3193.009 & 3126.404 & 458.76 & 0.00 & 0.846 \\
3 classes & $549.977(991)$ & 1.00 & 3047.512 & $\mathbf{3 1 6 7 . 2 8 8}$ & 3065.795 & 87.51 & 0.00 & 0.816 \\
4 classes & $495.966(979)$ & 1.00 & 3037.740 & 3198.689 & 3062.308 & 31.28 & 0.06 & 0.848 \\
\hline
\end{tabular}

Note. LR $\chi^{2}$ - Likelihood ratio chi-square; AIC - Akaike information criterion; BIC - Bayesian information criterion;

SSABIC - sample size adjusted BIC; LRT - Lo-Mendell-Rubin adjusted likelihood ratio test

the Lo-Mendell-Rubin LRT indicates that the 4-class model is not significantly better than the 3-class model; therefore the 3-class solution is preferred on the basis of parsimony. The entropy value (0.82) indicates acceptable classification of participants.

Figure 1 shows the latent class profile plot for criminal intent. The smallest class (Class 3) was labelled 'Low criminal intent' (9.4\% of the sample), and was considered to be the baseline (normative) or reference group. This class was characterised by low rates of endorsement for all of the MCAA items, particularly items 2 ("I could see myself lying to the police"), 5 ("I could easily tell a convincing lie") and 8 ("For a good reason, I would commit a crime"). Class 1 ('High criminal intent') was the largest class (49.3\% of participants) and was characterised by high probability of endorsing all items except item 9 ("I will break the law again"). Class $2(41.3 \%)$ is the intermediate class ('Intermediate criminal intent'), and was characterised by a fairly erratic pattern of item endorsement (i.e., high endorsement of some items [e.g., "I could see myself lying to the police and I would be happy to fool the police"], but not others [e.g., "Rules will not stop me from doing what I want" and "I will not break the law again"]). Although the probability levels follow the same increase/decreases pattern as that of the 'High criminal intent' class, the change in probability between the items is more significant between the items than those of the 'Low criminal intent' class. The 'High criminal intent' and 'Intermediate criminal intent' classes share similar profiles on items 2 ("I could see myself lying to the police") and 9 ("I will not break the law again"). However, the similarity on the latter is significantly more pronounced, showing an almost identical probability of endorsement.

\section{MULTINOMIAL LOGISTIC REGRESSION}

A multinomial logistic regression was used to analyse the relationship between recidivism and latent classes of criminal intent while controlling for type of offences (robbery, violent offences, murder and multiple offences), number of arrests, and age.
Table 4 presents the odds ratios attributed to each variable for each latent class in comparison to class three (the reference category). Results indicate that three variables have a significant effect on classification in the 'High criminal intent' group. Specifically, recidivism has a statistically significant positive effect on the classification in this 'High criminal intent' class $(\mathrm{OR}=1.78, p<0.01)$. Thus, the higher the level of recidivism, the more likely it is that the individual has a higher level of criminal intent. Also, higher age had a significant negative effect on 'High criminal intent' class membership ( $\mathrm{OR}=0.93, p<0.01)$. Finally, a significant negative effect was reported within the type of offending group. Violent offences were significantly less likely to have been committed by individuals belonging to the 'High criminal intent' class $(\mathrm{OR}=0.10, p<0.05)$.

With regards to the 'Intermediate criminal intent' group, the analysis showed no significant effects other than that of recidivism. The odds ratio shows a positive significant relationship between recidivism and 'Intermediate criminal intent' class membership $(\mathrm{OR}=1.79, p<0.05)$ in comparison to the reference class.

\section{DISCUSSION}

The main aim of the current study was to identity the appropriate number of latent classes of criminal intent within a large sample of violent and non-violent recidivistic prisoners, and to examine the association

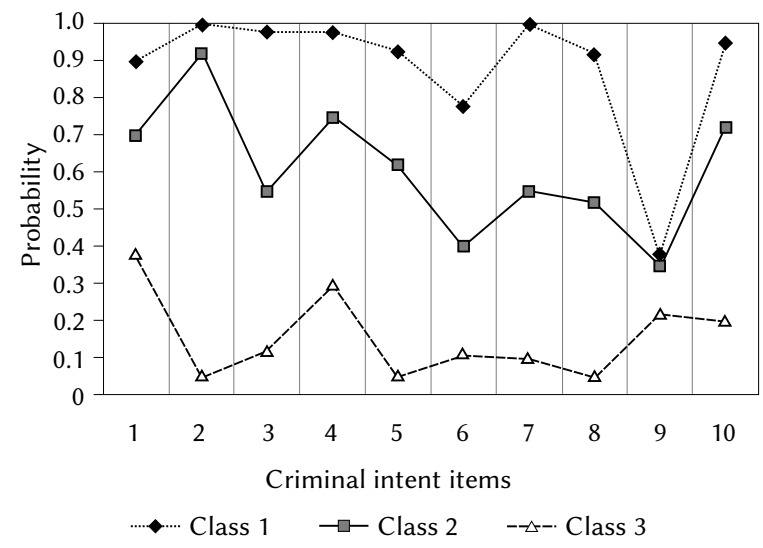

Figure 1. Latent class profile plot of criminal intent. 
Table 4

Associations between criminal thinking classes and age, number of police arrests, recidivism, and offense types

\begin{tabular}{ccccccc}
\hline Variable & \multicolumn{3}{c}{ Class 1 (high) } & \multicolumn{2}{c}{ Class 2 (intermediate) } \\
\cline { 2 - 7 } & $B$ & $S E$ & OR & $B$ & SE & OR \\
\hline Age & -0.07 & 0.03 & $0.93^{* *}$ & -0.03 & 0.03 & 0.97 \\
Number of arrests & 0.07 & 0.10 & 1.07 & -0.05 & 0.11 & 0.95 \\
Recidivism & 0.57 & 0.21 & $1.78^{* *}$ & 0.58 & 0.27 & $1.79^{* *}$ \\
Type of offending & & & & & \\
Robbery & Ref & & & & & \\
Violent offences & -2.27 & 1.03 & $0.10^{*}$ & -1.12 & 0.70 & 0.33 \\
Murder & -0.31 & 1.34 & 0.73 & -1.00 & 1.40 & 0.37 \\
Multiple offences & -0.29 & 0.86 & 0.75 & -1.60 & 1.03 & 0.20 \\
\hline Note. Reference group: Class 3 - low levels of criminal intent; $B$ - estimate; OR - odds ratio; $S E-$ standard error. ${ }^{*} p<0.055^{* *} p<0.01$
\end{tabular}

Note. Reference group: Class 3 - low levels of criminal intent; $B$ - estimate; OR - odds ratio; $S E-\operatorname{standard~error.~}{ }^{*} p<0.05 ;{ }^{* *} p<0.01$

between class membership and recidivism, while controlling for type of offences (robbery, violent offences, murder and multiple offences), number of arrests, and age. In order to determine the appropriate number of distinct latent classes of criminal intent (a specific component of criminal thinking), latent class analysis was conducted on data collected using the MCAA (Mills and Kroner, 1999).

Consistent with previous research (e.g., Boduszek \& Hyland, 2012; Walters, 2003; Walters, Frederick \& Schulauch, 2007), significant positive zero-order correlations were found between age, number of arrests, and recidivism, while age was negatively related to criminal intent. Also consistent with the finding of Walters et al. (2007), age was negatively associated with criminal intent, while both number of arrests and recidivism were associated with higher levels of criminal intent. Consequently, the findings offer further support for the crucial role of cognitive processes (in this case, criminal intent) in the presence of criminal conduct (Ajzen, 1988; Mills et al., 1998).

Results of the LCA indicated the presence of three latent classes. The classes were labelled as 'High criminal intent', 'Intermediate criminal intent' and 'Low criminal intent'. The baseline class was the 'Low criminal intent' group and consisted of less than ten percent of the sample. Prisoners in this class were characterised by low endorsement of all items of the antisocial intent subscale of the MCAA, particularly items 2, 5 and 8 . The remaining participants were divided relatively evenly between the 'Intermediate criminal intent' and 'Low criminal intent' classes, consisting of $41.3 \%$ and $49.3 \%$ of participants respectively. The 'Intermediate criminal intent' class contained individuals characterised by a somewhat erratic pattern of item endorsement. The final class, the 'Low criminal intent' class, included individuals who displayed high levels of endorsement across all items.
The latent profiles of the three criminal intent classes were extremely similar (i.e., the probabilities for the 'Low' and 'Intermediate' classes largely mirror those of the 'High' class, differing mainly in magnitude). This suggests that the latent classes are quantitatively, and not qualitatively distinct. This is consistent with a dimensional conceptualisation of criminal intent whereby individuals fall along a single continuum and differ only in terms of the intensity with which they endorse items.

Multinomial logistic regression analysis was conducted to estimate the association between latent classes of criminal intent and recidivism while controlling for type of offences (robbery, violent offences, murder and multiple offences), number of arrests, and age. The results of the regression analysis also, to some extent, support the continuum perspective, with the 'High criminal intent' class having the highest odds ratios (although significantly so in all cases), compared to the 'Intermediate' and 'Low' criminal intent classes, and with decreasing odds ratios from the 'High' to 'Low' class. This pattern was evident for the majority of predictor variables, with the exception of age and recidivism, which were greater in the 'Intermediate' class. Only one of the six investigated variables was significantly associated with belonging to the 'Intermediate criminal intent' class: recidivism. Results indicate that for every additional incarceration a person had, they were slightly less than twice as likely to belong to this criminal intent class compared to the Low criminal intent class. Number of arrests, murder, and multiple offences did not significantly predict membership in the 'High criminal intent' or 'Intermediate criminal intent' latent classes compared to the baseline 'Low criminal intent' class. By contrast, the results indicate that age, having committed a violent offence and recidivism were all significantly associated with 'High criminal intent' class membership. 
Recidivism was the strongest predictor of 'High criminal intent' group membership, the results indicating that for every additional incarceration a person had, they were slightly less than twice as likely to belong to this criminal intent class compared to the 'Low criminal intent' class. The association between recidivism and both 'High' and 'Intermediate' criminal intent class membership is consistent with research by Boduszek \& Hyland (2012) which found that criminal attitudes were significantly predicted by recidivism, and indicates that as the number of incarcerations an individual experiences increases, the greater is the likelihood that they will possess attitudes of a criminal nature. Moreover, the results suggest, as proposed by Rhodes (1979), Holsinger (1999), and Losel (2003), that socialisation in criminal environments (e.g., prisons) may lead to the acquisition and intensification of criminal attitudes (see also Walters, 2003). Consequently, the examination of criminogenic cognitions may prove useful in conjunction with, and not instead of, criminal history in the prediction of re-offending. The significant negative relationship between age and 'High criminal intent' group membership is consistent with previous research that has found that increasing age is associated with lower levels of criminal thinking (e.g., Dembo et al., 2007; Palmer \& Hollin, 2004; Walters, 2003) and the documented negative association between increasing age and desistence from offending (Farrington, Auty, Coid \& Turner, 2013), and suggests that offenders may grow out of criminal thinking. Another potential explanation for the inverse relationship among the high criminal intent group could be a proactive, reactive difference among this high group (Walters, Frederick \& Schlauch, 2007; Walters, 2009). The association between criminal intent group membership and only one offence type - violent offending - is consistent with the suggestion that criminogenic cognitions may not be engaged in equally by different offender groups (Polaschek et al., 2004; Wilson et al., 2003). The reason for the negative association between violent offenses and membership in the 'High criminal intent' group is, however, unclear. It may be that violent offenders' crimes are less planned or habitual than those of other offenders, and, therefore, they may be less inclined/willing to reoffend. Alternatively, due to the severity of their crimes, and their resultant sentence, they may have little intent to commit another crime, as they are facing lengthy sentences.

As with all research, the present study has a number of limitations that need to be taken into consideration when interpreting these findings. First, the nature of the sample is limited to a very specific group of criminals: male recidivistic criminals incarcerated in a maximum security setting. As Walters (1995a) found that maximum-security inmates endorsed higher levels of criminogenic cognitions on the PICTS than lower-security-level inmates, replication of the current analysis with more diverse criminal populations is clearly necessary. Second, participants were recruited from the Polish prison population and it is, therefore, unknown whether these results will generalise to samples drawn from alternative nationalities. Third, we did not use official records for the operationalization of recidivism but instead relied on prisoners' self-reports. Thus findings are open to distortion on the part of the offender and lacking the accuracy that official reports of recidivism would provide. However, as Maxfield, Weiler and Widom (2000) note, comparisons between self-reports and official records hold considerable concurrent validity. Finally, several variables that may contribute to criminal intent were explored within the present study, such as psychopathy (Dhingra \& Boduszek, 2013), criminal peer associations (Bourke, Boduszek \& Hyland, 2013), criminal social identity (Boduszek, Adamson, Shevlin \& Hyland, 2013), and personality traits (Bourke, Boduszek \& Hyland, 2013).

The reasons why prisoners favour a return to a criminal lifestyle (as indicated by high MCAA item endorsement; see Table 1) after incarceration is an important direction for future research. One possible explanation for this within the present research is the Polish economic system. A number of studies have shown that employment is a strong deterrent for criminal behaviour (e.g. Lochner, 2004; Myers, 1983), and Poland's employment rate has been unstable over the past few decades (Trading Economics, 2013).

The clearest finding, based on the current and previous research, is that younger offenders endorse higher levels of criminal thinking than older offenders. Consequently, intervention providers should target younger offenders, and seek to reduce their positive evaluations of criminal behaviour, as it follows that a change in attitude should reflect a change in the likelihood of the behaviour related to the object of the evaluation (Yochelson \& Samenow, 1976).

\section{CONCLUSIONS}

This study suggests that criminal intent consists of three distinct subgroups of individuals that differ quantitatively from each other. This indicates that criminal intent is a dimensional construct. Future work is needed to identify whether these distinct classes of criminal intent may predict engagement in various types of criminal behaviour. In general, this study reveals much about the different levels of criminal intent that exist among the criminal population, and identifies factors predictive of criminal intent class membership (i.e., age, recidivism, and offense type). Consequently, the current study adds important and original evidence to the literature on the nature and predictors of criminal intent. 


\section{References}

Ajzen, I. (1988). Attitudes, personality, and behaviour. Milton-Keynes, England: Open University Press.

Ajzen, I. \& Fishbein, M. (1980). Understanding attitudes and predicting social behavior. Englewood Cliffs, NJ: Prentice Hall.

Akers, R. (1985). Deviant Behaviour: A Social Learning Approach. Belmont: Wadsworth.

Andrews, K.H. \& Kandel, D.B. (1979). Attitude and behavior: A specification of the contingent consistency hypothesis. American Sociological Review, 44: 298-310.

Andrews, D.A., Zinger, I., Hoge, R.D., Bonta, J., Gendreau, P. \& Cullen, F.T. (1990). Does Correctional Treatment Work? A Clinically Relevant and Psychologically Informed Meta-Analysis. Criminology, 28, 369-404. doi: 10.1111/j.1745-9125.1990.tb01330.x.

Bagozzi, R.P. \& Burnkrant, R.E. (1979). Attitude organization and the attitude-behavior relationship. Journal of Personality and Social Psychology, 37, 913. doi: 10.1037/0022-3514.37.6.913.

Boduszek, D., Adamson, G., Shevlin, M. \& Hyland, P. (2013). Psycho-sociological investigation of criminal behaviour within a prison sample using retrospective data. The Howard Journal of Criminal Justice (accepted for publication) (ISSN 1468-2311).

Boduszek, D. \& Hyland, P. (2012). Psycho-Sociological Review of Criminal Thinking. Journal of $\mathrm{Hu}$ manistics and Social Sciences, 1, 28-36.

Boduszek, D., Hyland, P., Shevlin, M. \& Adamson, G. (2013). Assessment of Psycho-Social Factors Predicting Recidivistic Violent Offences within a Sample of Male Prisoners. Irish Journal of Psychology (in press). doi: 10.1080/03033910.2012.754324.

Boduszek, D., McLaughlin, C. \& Hyland, P. (2011). Criminal Attitudes of Ex-Prisoners: the Role of Personality, Anti-Social Friends and Recidivism. The Internet Journal of Criminology, 9, 1-10.

Bourke, A., Boduszek, D. \& Hyland, P. (2013). The role of criminal cognitions and personality traits in non-violent recidivism: Empirical investigation within a prison sample. Journal of Criminal Psychology, 3, 40-48. doi: 10.1108/20420921211236771.

Caprara, G.V., Cinanni, V. \& Mazzotti, E. (1989). Measuring attitudes toward violence. Personality and Individual Differences, 10, 479-481. doi: 10.1016/ 0191-8869(89)90014-7.

Dembo, R., Turner, C.W. \& Jainchill, N. (2007). Criminal thinking among incarcerated youths in three states. Criminal Justice and Behaviour, 34, 11571168. doi: 10.1177/0093854807304348.

Dhingra, K. \& Boduszek, D. (2013). Psychopathy and Criminal Behaviour: A Psychosocial Research Perspective. Journal of Criminal Psychology, 3, 1-25.

Engels, R.C., Luijpers, E., Landsheer, J. \& Meeus, W. (2004). A longitudinal study of relations between attitudes and delinquent behavior in adolescents.
Criminal Justice and Behavior, 31, 244-260. doi: 10.1177/0093854803261344.

Farrington, D.P., Auty, K.M., Coid, J.W. \& Turner, R.E. (2013). Self-Reported and Official Offending from Age 10 to Age 56. European Journal on Criminal Policy and Research, 1-17. doi: 10.1007/s10610-0129195-x.

Gendreau, P., Goggin, C.E. \& Law, M.A. (1997). Predicting prison misconducts. Criminal Justice and Behavior, 24, 414-431. doi: 10.1177/009385489702400 4002.

Gendreau, P., Little, T. \& Goggin, C. (1996). A metaanalysis of the predictors of adult offender recidivism: What works! Criminology, 34, 575-607. doi: 10.1111/j.1745-9125.1996.tb01220.x.

Hanson, R.K. \& Harris, A.J. (2000). Where should we intervene? Dynamic predictors of sexual offense recidivism. Criminal Justice and Behavior, 27, 6-35. doi: $10.1177 / 0093854800027001002$.

Hanson, R.K. \& Thornton, D. (1999). Static 99: Improving actuarial risk assessments for sex offenders (Vol. 2). Solicitor General Canada.

Hatch-Maillette, M.A., Scalora, M.J., Huss, M.T. \& Baumgartner, J.V. (2001). Criminal thinking patterns: Are child molesters unique? International Journal of Offender Therapy and Comparative Criminology, 45, 102-117. doi: 10.1177/0306624X 01451007.

Holsinger, A.M. (1999). Assessing criminal thinking: Attitudes and orientations influence behavior. Corrections Today, 61, 22-25.

Jackson, D.N. (1989). Basic Personality Inventory Manual. London, Canada: Sigma Assessment Systems.

Kroner, D.G., Holden, R.R. \& Reddon, J.R. (1997). Validity of the Basic Personality Inventory in a correctional setting. Assessment, 4, 141-154. doi: 10. 1177/107319119700400204.

Kroner, D.G. \& Mills, J.F. (1998). The structure of antisocial attitudes among violent and sexual offenders. International Journal of Offender Therapy and Comparative Criminology, 42, 246-257. Lochner, L. (2004). Education, work, and crime: A human capital approach. International Economic Review, 45, 811-843. doi: 10.1111/j.0020-6598. 2004.00288.x.

Losel, F. (2003). The development of delinquent behaviour. In: D. Carson \& R. Bull (eds.). Handbook of Psychology in Legal Context ( $2^{\text {nd }}$ ed.). England: John Wiley and Sons, Ltd.

Mandracchia, J.T. \& Morgan, R.D. (2012). Predicting offenders' criminogenic cognitions with status variables. Criminal Justice and Behavior, 39, 5-25. doi: 10.1177/0093854811425453.

Mandracchia, J.T. \& Morgan, R.D. (2010). The relationship between status variables and criminal thinking in an offender population. Psychological Services, 7, 27. doi: 10.1037/a0016194.

Maxfield, M.G., Weiler, B.L. \& Widom, C.S. (2000). Comparing self-reports and official records of ar- 
rests. Journal of Quantitative Criminology, 16, 87110. doi: 10.1023/A:1007577512038.

Maruna, S. \& Copes, H. (2005). What have we learned from five decades of neutralization research? Crime and Justice, 32, 221-320.

Mills, J.F., Anderson, D. \& Kroner, D.G. (2004). The antisocial attitudes and associates of sex offenders. Criminal Behaviour and Mental Health, 14, 134-145. doi: 10.1002/cbm.578.

Mills, J.F. \& Kroner, D.G. (1999). Measures of Criminal Attitudes and Associates (MCAA). Unpublished instrument and user guide.

Mills, J.F. \& Kroner, D.G. (2001). Measures of Criminal Attitudes and Associates (MCAA). Unpublished instrument and user guide.

Mills, J.F., Kroner, D.G. \& Forth, A.E. (2002). Measures of Criminal Attitudes and Associates (MCAA) Development, Factor Structure, Reliability, and Validity. Assessment, 9, 240-253. doi: 10.1177/ 1073191102009003003.

Mills, J.F., Kroner, D.G. \& Hemmati, T. (2004). The Measures of Criminal Attitudes and Associates (MCAA) The Prediction of General and Violent Recidivism. Criminal Justice and Behavior, 31, 717733. doi: $10.1177 / 0093854804268755$.

Mills, J.F., Kroner, D.G. \& Weekes, J.R. (1998). Anger and institutional misconduct in a sample of violent offenders. Unpublished manuscript.

Myers, S. (1983). Estimating the economic model of crime: employment versus punishment effects. The Quarterly Journal of Economics, 98, 157-166. doi: 10.2307/1885572.

Palmer, W. (1997). A new scheme for predicting recidivism. Unpublished doctoral dissertation, Queen's University, Kingston, Ontario, Canada.

Palmer, E.J. \& Hollin, C.R. (2004). Predicting reconviction using the psychological inventory of criminal thinking styles with English prisoners. Legal and Criminological Psychology, 9, 57-68. doi: 10.1348/135532504322776852.

Polaschek, D.L.L., Collie, R.M. \& Walkey, F.H. (2004). Criminal attitudes to violence: Development and preliminary validation of a scale for male prisoners. Aggressive Behavior, 30, 484-503. doi: 10.1002/ ab.20081.

Quinsey, V.L., Harris, G.T., Rice, M.E. \& Cormier, C.A. (1998). Violent offenders: Appraising and managing risk. Washington DC.

Ragatz, L.L., Fremouw, W. \& Baker, E. (2012). The Psychological Profile of White-collar Offenders Demographics, Criminal Thinking, Psychopathic Traits, and Psychopathology. Criminal Justice and Behavior, 39, 978-997. doi: 10.1177/0093854812437846.

Rhodes, M.L. (1979). The impact of social anchorage on prisonization. Dissertation Abstracts International, 40, 1694A (UMI No. 79-19, 101).

Simourd, D.J., Hoge, R.D., Andrews, D.A., \& Leschied, A.W. (1994). An empirically-based typolo- gy of male young offenders. Canadian Journal of Criminology, 36, 447-461.

Simourd, D.J. \& Olver, M.E. (2002). The future of criminal attitudes research and practice. Criminal Justice and Behavior, 29, 427-446.

Simourd, D.J. \& Van De Ven, J. (1999). Assessment of Criminal Attitudes Criterion-Related Validity of the Criminal Sentiments Scale-Modified and Pride in Delinquency Scale. Criminal Justice and Behavior, 26, 90-106. doi: 10.1177/00938548990260 01005.

Sutherland, E.H. \& Cressey, D.R. (1960). Principles of Criminology (6 ${ }^{\text {th }}$ ed.) Philadelphia: Lippincott.

Sykes, G.M. \& Matza, D. (1957). Techniques of neutralization: A theory of delinquency. American Sociological Review, 22, 664-670.

Trading Economics (2013). Poland unemployment rate. Retrieved $31^{\text {st }}$ July. Online available at: http:// www.tradingeconomics.com/poland/unemployment-rate.

Walters, G.D., Elliott, W.N. \& Miscoll, D. (1998). Use of the Psychological Inventory of Criminal Thinking Styles in a group of female offenders. Criminal Justice and Behavior, 25, 125-134. doi: 10.1177/ 0093854898025001008.

Walters, G.D., Frederick, A.A. \& Schlauch, C. (2007). Postdicting arrests for proactive and reactive aggression with the PICTS Proactive and Reactive composite scales. Journal of interpersonal violence, 22, 1415-1430.

Walters, G.D. \& Geyer, M.D. (2004). Criminal thinking and identity in male white-collar offenders. Criminal Justice and Behavior, 31, 263-281. doi: 10.1177/ 0093854803262508.

Walters, G.D. (2009). Anger management training in incarcerated male offenders: Differential impact on proactive and reactive criminal thinking. International Journal of Forensic Mental Health, 8, 214-217.

Walters, G.D. (1990). The criminal lifestyle: Patterns of serious criminal conduct. Sage.

Walters, G.D. (1995a). The Psychological Inventory of CriminalThinking Styles: Part I. Reliability and preliminary validity. Criminal Justice and Behaviour, 22, 307-325. doi: 10.1177/0093854895022003008.

Walters, G.D. (1995b). The Psychological Inventory of Criminal Thinking Styles. Part II: Identifying simulated response sets. Criminal Justice and Behavior, 22, 437-445. doi: 10.1177/0093854895022004007.

Walters, G.D. (2002). The Psychological Inventory of Criminal Thinking Styles (PICTS): A review and meta-analysis. Assessment, 9, 283-296. doi: 10.1177/ 1073191102009003007.

Walters, G.D. (2003). Changes in criminal thinking and identity in novice and experienced inmates: Prisonization revisited. Criminal Justice and $\mathrm{Be}$ havior, 30, 399-421. doi: 10.1177/0093854803253137.

Walters, G.D. (2006). Appraising, researching and conceptualizing criminal thinking: a personal view. 
Criminal Behaviour and Mental Health, 16: 87-99. doi: 10.1002/cbm.50.

Walters, G.D. \& Elliott, W.N. (1999). Predicting release and disciplinary outcome with the Psychological Inventory of Criminal Thinking Styles: Female data. Legal and Criminological Psychology, 4, 15-21. doi: 00.1348/135532599167743.

Walters, G.D. \& Schlauch, C. (2008). The Psychological Inventory of Criminal Thinking Styles and Level of Service Inventory-Revised: Screening Version as predictors of official and self-reported disciplinary infractions. Law and Human Behavior, 32, 454-462. doi: 10.1007/s10979-007-9117-5.

Walters, G.D., Frederick, A.A. \& Schlauch, C. (2007). Postdicting arrests for proactive and reactive aggression with the PICTS Proactive and Reactive composite scales. Journal of Interpersonal Violence, 22, 1415-1430.

Walters, G.D. \& White, T.W. (1989). The thinking criminal: A cognitive model of lifestyle criminality. Criminal Justice Research Bulletin, 4, 1-10.

Wilson, S., Attrill, G. \& Nugent, F. (2003). Effective interventions for acquisitive offenders: An investigation of cognitive skills programmes. Legal and Criminological Psychology, 8, 83-101. doi: 10.1348/ 135532503762871264.

Yochelson, S. \& Samenow, S.E. (1976). The Criminal Personality. Vol. 1. A Profile for Change. New York: Jason Aronson. 